\title{
Metformin potentiates the anticancer effects of cisplatin under normoxic conditions in vitro
}

\author{
TAKASHI UEHARA $^{1}$, AKIRA MITSUHASHI $^{1}$, NOBUHIDE TSURUOKA $^{1,2}$ and MAKIO SHOZU ${ }^{1}$ \\ Departments of ${ }^{1}$ Reproductive Medicine, ${ }^{2}$ Developmental Genetics, Graduate School of Medicine, \\ Chiba University, Chuo-ku, Chiba 260-8670, Japan
}

Received June 17, 2014; Accepted September 19, 2014

DOI: 10.3892/or.2014.3611

\begin{abstract}
Metformin is a diabetes drug with anticancer properties. Several studies have investigated the effects of metformin combined with chemotherapeutic agents, with controversial results. This study evaluated the efficacy of combined metformin/cisplatin treatment in an endometrial cancer cell line. Ishikawa cells were treated with metformin, cisplatin or both types of treatment. Cell proliferation was evaluated by quantification and colorimetric and thymidine incorporation assays, cell cycle progression was assessed by flow cytometry, and apoptosis by the caspase- 3 activity assay. The effects of metformin and cisplatin used in combination were assessed under normoxic $\left(21 \% \mathrm{O}_{2}\right)$ and hypoxic $\left(1 \% \mathrm{O}_{2}\right)$ conditions. Mitochondrial morphology was examined using the MitoTracker dye, while function was assayed by lactate production. Discrepant results were obtained from the different assays of cell proliferation, with the value obtained from the colorimetric assay being higher than that from cell counts after drug treatment. Combined treatment with metformin $(\geq 2 \mathrm{mM})$ and cisplatin $(1 \mu \mathrm{M})$ had additive anti-proliferative effects on cells under normoxic conditions. However, the additive effect of metformin was attenuated under hypoxia. Metformin caused morphological and functional changes in mitochondria, which appeared shortened after exposure to metformin, while the connections between individual mitochondria appeared weaker. Additionally, decreased MitoTracker staining was observed after an 8-h exposure to metformin. The colorimetric assay did not accurately determine the effects of metformin and cisplatin on cell proliferation. The additive effects of metformin on cisplatin-induced inhibition of cell proliferation were attenuated under hypoxic conditions, while metformin compromised mitochondrial structure and function. Additional studies are needed to determine the efficacy of this drug combination in vivo.
\end{abstract}

Correspondence to: Dr Takashi Uehara, Department of Reproductive Medicine, Graduate School of Medicine, Chiba University, 1-8-1 Inohana, Chuo-ku, Chiba 260-8670, Japan

E-mail: takuehar@chiba-u.jp

Key words: cisplatin, combination treatment, endometrial cancer, hypoxia, metformin

\section{Introduction}

Several epidemiological studies and systematic reviews have identified a lower cancer prevalence among patients with type 2 diabetes mellitus who take metformin (1-3), and recent in vitro and in vivo studies have shown that metformin inhibits cancer cell proliferation $(4,5)$. Cytotoxic chemotherapy has long been used to treat cancer. Focus has been placed on the use of metformin combined with other drugs to improve treatment efficacy $(4,5)$.

Although recent studies have assessed combination treatment approaches with metformin in vitro (6-20), the findings have been controversial. First, the concentrations of metformin used in the majority of these studies were much higher $(0.5-20 \mathrm{mM})$ than the clinically relevant doses $(4,5,21,22)$, and it is therefore unclear whether those concentrations are effective for cancer treatment $(4,5)$. Second, results from the aforementioned studies have also been controversial, with some reports describing a synergistic or additive effect of combined drug treatment $(6-17,19,20)$, while antagonistic effects were observed in tumor cells of the brain, blood, soft tissue, and lung (with the exception of adenocarcinomas) as well as adriamycin-resistant breast cancer cells, where the majority of these cells were non-carcinoma or specific types of carcinoma cells $(10,12,14,16,18)$. In addition, metformin was shown to accelerate the growth of BRAFV600E-driven melanoma (23). Thus, the anti-proliferative effects of metformin may be cancer type-specific.

These contradictory findings may be due to differences in methodology and quantification. Colorimetric assays such as the 3-(4,5-dimethylthiazol-2-yl)-2,5-diphenyl tetrazolium bromide (MTT) assay have been widely used in high-throughput drug screens that are based on the assessment of cell proliferation or viability $(24,25)$. Several agents that can influence the results of colorimetric assays have been recognized, such as the production of reactive oxygen species by mitochondria (26), as well as drugs that induce G2/M cell cycle arrest which can lead to an increase in cell size, which in turn affect the results of the MTT assay (27). Thus, caution must be applied to the interpretation of results from colorimetric assays.

Endometrial cancer patients may benefit from combination drug treatment for the following reasons. First, metformin improves resistance to insulin, which is believed to play a role in the development of endometrial cancer (28-30). Second, 
chemotherapy has been successfully used to treat endometrial cancer $(31,32)$. In two recent in vitro studies, the efficacy of combination treatment on endometrial cancer cell lines using colorimetric assays to analyze cell proliferation was investigated (6,7). However, experiments conducted in those studies used metformin concentrations of 0.5 and $1.0 \mathrm{mM}$ which, as explained above, may lead to unreliable conclusions $(6,7)$. We therefore examined the effects of combined metformin and cisplatin treatment in an endometrial cancer cell line using various assays to measure cell proliferation and other parameters associated with cancer progression.

\section{Materials and methods}

Cell culture. The Ishikawa endometrial cancer cell line was grown in Dulbecco's modified Eagle's medium supplemented with $4.5 \mathrm{~g} / \mathrm{l}$ glucose, $10 \%$ fetal bovine serum, $100 \mathrm{U} / \mathrm{ml}$ penicillin, $100 \mu \mathrm{g} / \mathrm{ml}$ streptomycin, and $100 \mu \mathrm{g} / \mathrm{ml} \mathrm{kanamycin}$ sulfate (all from Life Technologies, Carlsbad, CA, USA) at $37^{\circ} \mathrm{C}$ in a humidified atmosphere of $5 \% \mathrm{CO}_{2}$ and $21 \% \mathrm{O}_{2}$ for normoxic or $1 \% \mathrm{O}_{2}$ for hypoxic conditions. A range of concentrations was assessed for cisplatin (0-5 $\mu \mathrm{M})$ (Bristol-Myers-Squibb, New York, NY, USA) and metformin (0-10 mM) (Sigma Aldrich, St. Louis, MO, USA) in the cell proliferation assay. Subsequent experiments using a combination of the two drugs were performed with $0-2 \mathrm{mM}$ metformin and $1 \mu \mathrm{M}$ cisplatin.

Cell quantification. Cells were counted as an index of cell proliferation. A total of $2 \times 10^{3}$ cells/well was seeded in 96-well plates and incubated for $24 \mathrm{~h}$. The medium was replaced, and metformin and/or cisplatin were added as indicated. After $48 \mathrm{~h}$, the cells were observed using a light microscope (Diaphot-TMD; Nikon, Tokyo, Japan) and counted using a hemocytometer.

Colorimetric assay. The MTT assay was used to assess cell viability. This colorimetric assay measures the absorbance of formazan molecules that are produced by the reduction of the tetrazolium salt by cellular enzymes. The protocol was performed according to the manufacturer's instructions. Briefly, cells were seeded in 96-well plates at $2 \times 10^{3}$ cells/well and incubated for $24 \mathrm{~h}$. The medium was replaced, and metformin and/ or cisplatin were added as indicated. After $48 \mathrm{~h}$, the chromogenic reagent was added to the culture medium for $3 \mathrm{~h}$. After removing the culture medium, the formazan crystals were dissolved by adding isopropanol and dimethyl sulfoxide, and absorbance at $570 \mathrm{~nm}$ was measured using an automated microplate reader (Infinite 200; Tecan, Männedorf, Switzerland).

Cell size measurement. Changes in cell size after treatment with metformin or cisplatin were determined from images obtained by light microscopy. A total of $2 \times 10^{4}$ cells/well was seeded in 12-well plates and incubated for $24 \mathrm{~h}$, then treated with metformin or cisplatin for $48 \mathrm{~h}$. The cells were observed and imaged using a light microscope (Diaphot-TMD; Nikon). The cell area was measured from the images of 100 cells for each drug concentration using ImageJ software (National Institutes of Health, Bethesda, MD, USA).

Flow cytometry. The effect of drug treatment on the cell cycle was determined by flow cytometry, using the CycleTEST
PLUS DNA Reagent kit (Becton-Dickinson, Franklin Lake, NJ, USA) according to the manufacturer's instructions. The kit enabled the isolation of cells with propidium iodide-stained nuclei. Between $1 \times 10^{5}$ and $1 \times 10^{6}$ cells were seeded in a $6-\mathrm{cm}$ dish and incubated for $24 \mathrm{~h}$. The medium was replaced and combinations of metformin $(0,0.1$ and $2.0 \mathrm{mM})$ and cisplatin $(1 \mu \mathrm{M})$ were added. The cells were sorted $48 \mathrm{~h}$ later using a FACSCalibur flow cytometer (Becton-Dickinson).

Caspase activity assay. Caspase activity was determined using the Caspase-Glo 3/7 assay (Promega, Madison, WI, USA) $48 \mathrm{~h}$ after drug treatment. This assay is based on the cleavage of a caspase-3/7 substrate, which produces a free aminoluciferin that is consumed by luciferase and generates a luminescent signal proportional to caspase activity. The protocol was performed according to the manufacturer's instructions. A total of $2 \times 10^{3}$ cells/well was seeded in 96-well plates and incubated for $24 \mathrm{~h}$. The medium was then replaced and combinations of metformin $(0-2 \mathrm{mM})$ and cisplatin $(1 \mu \mathrm{M})$ were added. After $48 \mathrm{~h}$, the caspase-3/7 substrate was added to the culture medium for $60 \mathrm{~min}$, and luciferase activity was measured using an automated microplate luminometer (Infinite 200; Tecan). Cells in other wells were also counted with a hemocytometer using a microscope. Luminescence values were divided by the total number of counted cells to calculate the luminescence per cell.

Thymidine incorporation assay. The thymidine incorporation assay, which quantifies $\left[{ }^{3} \mathrm{H}\right]$ thymidine uptake during DNA synthesis, was used to measure cell proliferation. A total of $2 \times 10^{3}$ cells/well was seeded in 96 -well plates and incubated for $24 \mathrm{~h}$. The culture medium was replaced and metformin $(0-10 \mathrm{mM})$ or cisplatin $(0-5 \mu \mathrm{M})$ was added for $48 \mathrm{~h}$, or combinations of metformin $(0-5 \mathrm{mM})$ and cisplatin $(0-5 \mu \mathrm{M})$ were added for $24 \mathrm{~h}$, followed by $\left[{ }^{3} \mathrm{H}\right]$ thymidine for $3 \mathrm{~h}$. The experiment for combination treatments was performed under normoxic and hypoxic conditions, since many types of tumor cell are thought to tolerate hypoxia in vivo.

Mitochondrial and nuclear staining. Mitochondria were stained with MitoTracker Red CMXRos (Life Technologies) according to the manufacturer's instructions. A total of $4 \times 10^{4}$ cells/well was seeded in 6 -well plates or glass-bottom dishes (for imaging) and incubated for $24 \mathrm{~h}$. The medium was replaced and metformin was added for 8 or $48 \mathrm{~h}$. The staining solution was prepared at a concentration of $100 \mathrm{nM}$ and added to the culture medium. After a 15-min incubation, the cells were washed with PBS and fluorescence was observed by confocal microscopy (FV10i-LIV; Olympus, Tokyo, Japan) and analyzed by flow cytometry. Nuclei were stained with Hoechst 33342 (1 $\mu \mathrm{g} / \mathrm{ml})$ (Dojindo, Kumamoto, Japan) for $20 \mathrm{~min}$ and then washed with PBS.

Measurement of lactate concentration. Lactate concentration in the cell culture medium was used as a measure of mitochondrial function. A total of $2-2.5 \times 10^{4}$ cells/well was seeded in 12-well plates and incubated for $24 \mathrm{~h}$, then treated with metformin as indicated. The medium was collected and lactate concentrations were measured $48 \mathrm{~h}$ later. The cells were also counted with a hemocytometer using a microscope. 
A

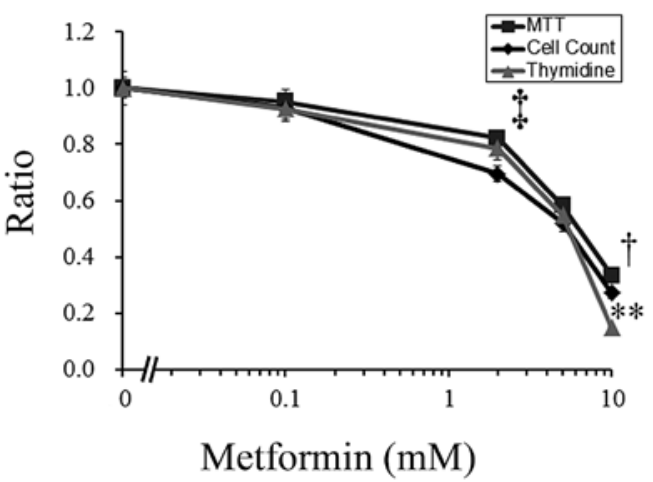

B

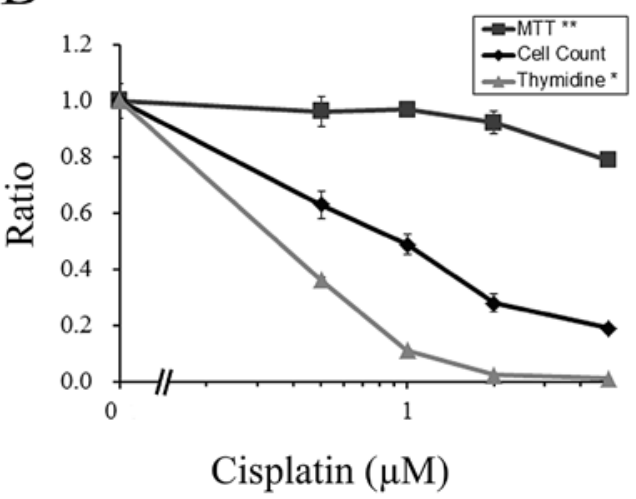

Figure 1. Assessment of Ishikawa cell proliferation using three different methods. Proliferation was evaluated relative to control cells by cell counts, and the MTT or thymidine incorporation assays in cells treated with the indicated doses of (A) metformin (MET) or (B) cisplatin (CDDP) for $48 \mathrm{~h}$. The two drugs inhibited proliferation in a dose-dependent manner. The fraction of proliferating cells determined by MTT or thymidine incorporation assays was compared to the fraction determined from counts at the same dose of MET or CDDP. Data are shown as the mean \pm standard error of triplicate samples from three independent experiments. ${ }^{\dagger} \mathrm{P}<0.05,{ }^{\dagger} \mathrm{P}<0.01,{ }^{*} \mathrm{P}<0.005$ and ${ }^{* *} \mathrm{P}<0.001$.

The lactate concentration was divided by the total number of counted cells to calculate the lactate production per cell.

Statistical analysis. Data are shown as the mean \pm standard error. Data were analyzed with SPSS ver. 21.0 (SPSS Inc., Chicago, IL, USA) using the Student's t-test, except for flow cytometry data for which the Mann-Whitney U test was used. $\mathrm{P}<0.05$ was considered statistically significant.

\section{Results}

Cell proliferation and cell viability assays yield discrepant results. Cell proliferation was assessed by cell counts as well as colorimetric and thymidine incorporation assays in Ishikawa cells treated for $48 \mathrm{~h}$ with metformin or cisplatin. Each drug alone inhibited cell proliferation in a dose-dependent manner, as determined by cell counts (Fig. 1). However, significant discrepancies were observed between these results and those of the colorimetric and thymidine incorporation assays. For instance, at $10 \mathrm{mM}$ metformin, the proliferative fraction as measured by thymidine incorporation and the MTT assay was $46 \%$ lower and $23 \%$ higher, respectively, than the value
Table I. Cell size (area) in Ishikawa cells treated with MET or CDDP.

\begin{tabular}{lc} 
Drug treatment & Cell area (ratio) \\
\hline Control & $1.00 \pm 0.06$ \\
CDDP $0.5 \mu \mathrm{M}^{\mathrm{a}}$ & $1.30 \pm 0.10$ \\
CDDP $2 \mu \mathrm{M}^{\mathrm{a}}$ & $2.33 \pm 0.15$ \\
MET $2 \mathrm{mM}^{\mathrm{a}}$ & $0.84 \pm 0.04$ \\
MET $10 \mathrm{mM}^{\mathrm{a}}$ & $0.63 \pm 0.03$ \\
\hline
\end{tabular}

${ }^{\mathrm{a}} \mathrm{P}<0.05$. MET, metformin; CDDP, cisplatin.

obtained from the cell counts (Fig. 1A). Similarly, at a cisplatin concentration of $0.5 \mu \mathrm{M}$, the proliferative fraction as measured by thymidine incorporation was $\sim 43 \%$ lower than the value obtained by the cell counts, while the fraction determined using the MTT assay was almost 53\% higher (Fig. 1B). A similar trend was observed for higher concentrations of cisplatin. As results from the colorimetric assay were consistently higher than values obtained from the cell counts, the assay was not used further in this study to assess cell proliferation.

Cisplatin induces the enlargement of endometrial cancer cells. Cell size was measured to determine the efficacy of each drug. Treatment with cisplatin at concentrations of 0.5 and $2 \mu \mathrm{M}$ led to an increase in cell size compared to the control cells, while treatment with metformin at concentrations of 2 and $10 \mathrm{mM}$ led to a decrease in cell size compared to the control cells (Table I).

Metformin potentiates the anticancer effects of cisplatin in endometrial cancer cells. The combined treatment of metformin and cisplatin had additive, dose-dependent, anticancer effects compared to the cells treated with cisplatin alone (Fig. 2). For instance, $0.1 \mathrm{mM}$ metformin $+1 \mu \mathrm{M}$ cisplatin had no effect on cell numbers, but a higher concentration of metformin $(2 \mathrm{mM})$ with cisplatin reduced proliferation by $20 \%$ (Fig. 2A). Similarly, following the treatment of cells with $2 \mathrm{mM}$ metformin $+1 \mu \mathrm{M}$ cisplatin, thymidine incorporation was decreased by a similar amount (Fig. 2B). Caspase activity and G1/S arrest also increased slightly, although these differences were not statistically significant $(\mathrm{P}=0.052$ and 0.083 , respectively) (Fig. 2C and D).

Anticancer effects of combined metformin and cisplatin treatment are attenuated under hypoxic conditions. Metformin has been reported to inhibit complex I of the mitochondrial respiratory chain $(33,34)$, suggesting that the anticancer effects of combined metformin and cisplatin treatment could be compromised under hypoxic conditions. Notably, while thymidine incorporation was reduced in cells treated with 2 or $5 \mathrm{mM}$ metformin and various concentrations of cisplatin $(0-5 \mu \mathrm{M})$ relative to cells treated with cisplatin alone under normoxic conditions (Fig. 3Aa and $\mathrm{Ba}$ ), these differences were attenuated when cells were subjected to hypoxia (Fig. 3Ab and $\mathrm{Bb}$ ).

Metformin treatment inhibits mitochondrial function. To examine the effects of metformin on mitochondria, the cells 
A

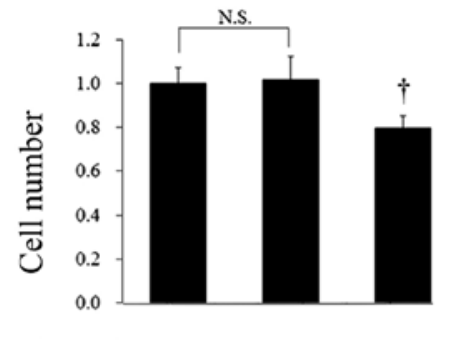

$\operatorname{CDDP}(1 \mu \mathrm{M})+++$

MET

$\begin{array}{lll}- & 0.1 & 2.0\end{array}$

C

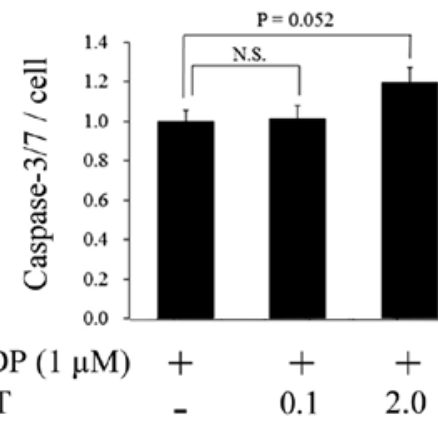

B

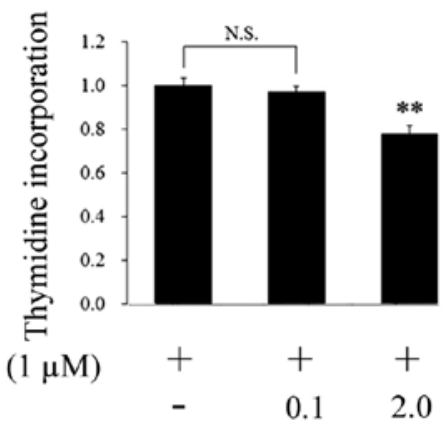

D
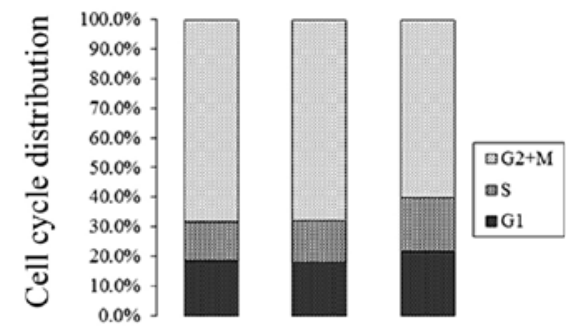

$\operatorname{CDDP}(1 \mu \mathrm{M})$

MET
- $\quad 0.1 \quad 2.0$

Figure 2. Metformin (MET) potentiates the anticancer effects of cisplatin (CDDP) in a dose-dependent manner. The combination of $2 \mathrm{mM}$ MET with $1 \mu \mathrm{M}$ CDDP decreased (A) cell proliferation and (B) thymidine incorporation. (C) Caspase activity increased slightly. (D) Slight increases in cell cycle arrest were noted, however, these increases did not reach statistical significance. Data are shown as the mean \pm standard error of triplicate samples from (A-C) three independent experiments and (D) a total of four samples from each of four independent experiments. ${ }^{\dagger} \mathrm{P}<0.05$ and ${ }^{* *} \mathrm{P}<0.001$. N.S., not significant.

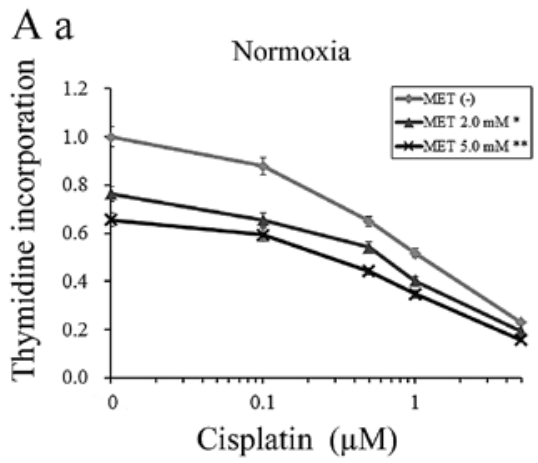

$\mathrm{B}$ a

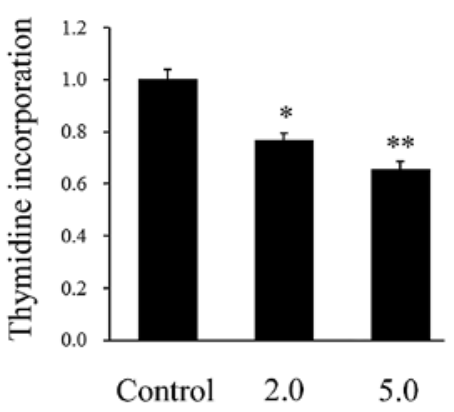

MET

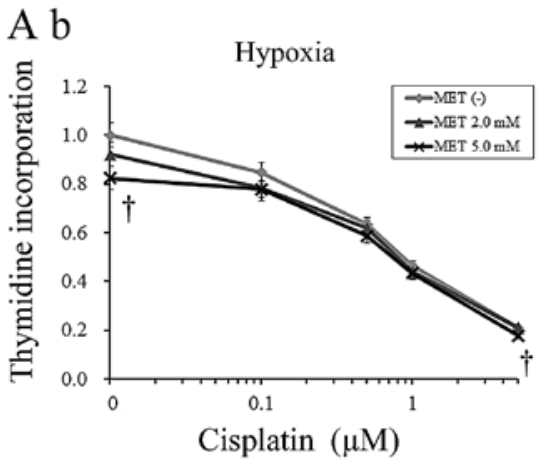

$\mathrm{B} \mathrm{b}$

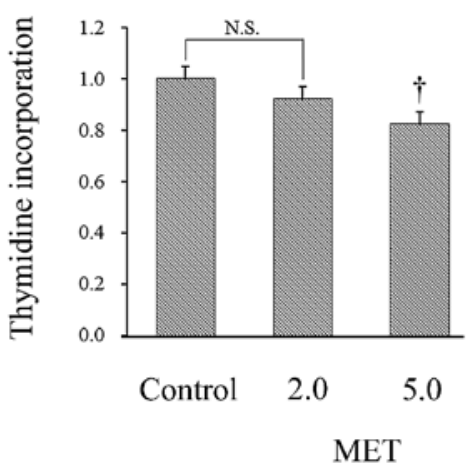

Figure 3. Effect of combined metformin (MET) and cisplatin (CDDP) treatment on thymidine incorporation in Ishikawa cells cultured at different $\mathrm{O}_{2}$ levels. (Aa) In cells cultured under normoxic conditions $\left(21 \% \mathrm{O}_{2}\right)$, higher concentrations of MET resulted in a greater reduction in thymidine incorporation relative to cells treated with CDDP only. (Ab) The additive effects of MET and CDDP were attenuated under hypoxic conditions $\left(1 \% \mathrm{O}_{2}\right)$. Data for MET are shown only for the $5 \mathrm{mM}$ concentration, although results at $2 \mathrm{mM}$ were not significant. (B) A greater reduction in thymidine incorporation following MET treatment was $(\mathrm{Ba})$ observed under normoxic $(\mathrm{Bb})$ compared to hypoxic conditions. Data are shown as mean \pm standard error of six samples from three independent experiments. ${ }^{\dagger} \mathrm{P}<0.05,{ }^{*} \mathrm{P}<0.005$ and ${ }^{* *} \mathrm{P}<0.001$. N.S., not significant. 
Aa

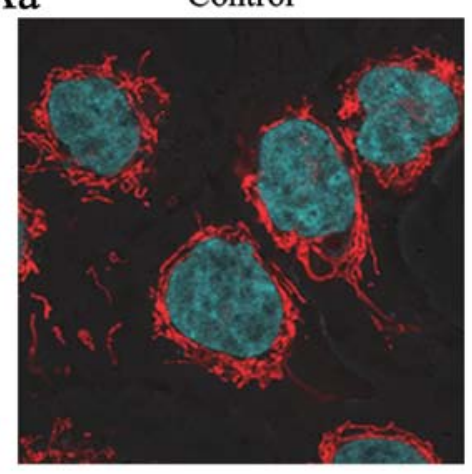

B

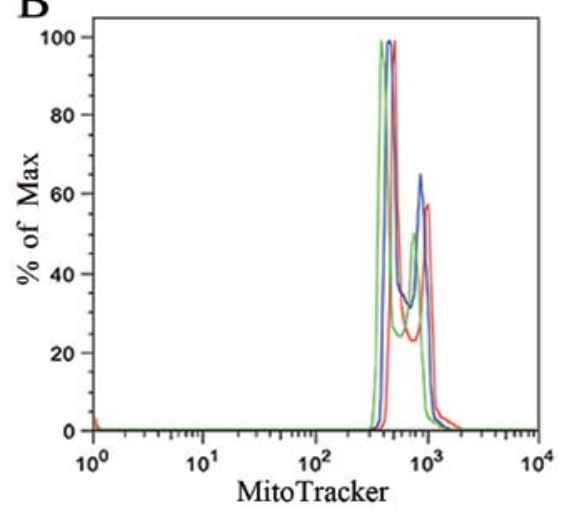

$\mathrm{Ab}$

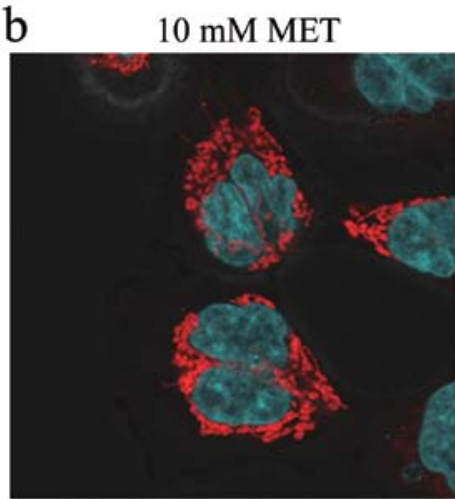

$\mathrm{Ca}$
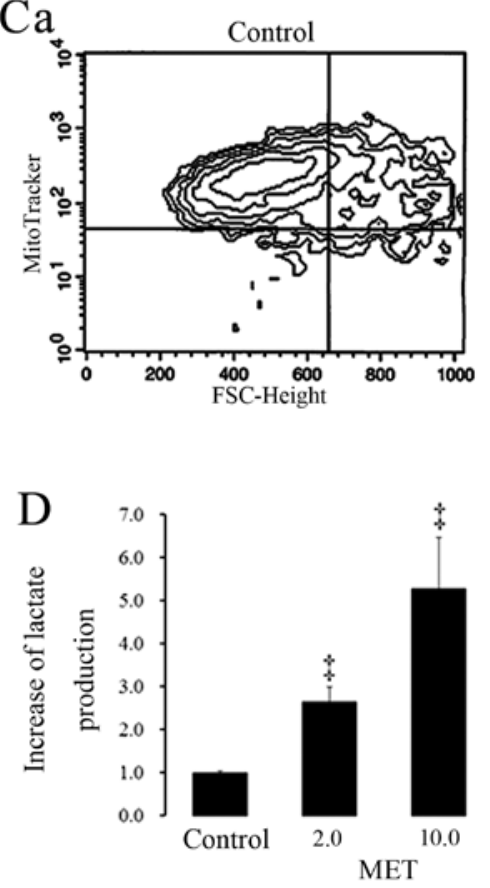

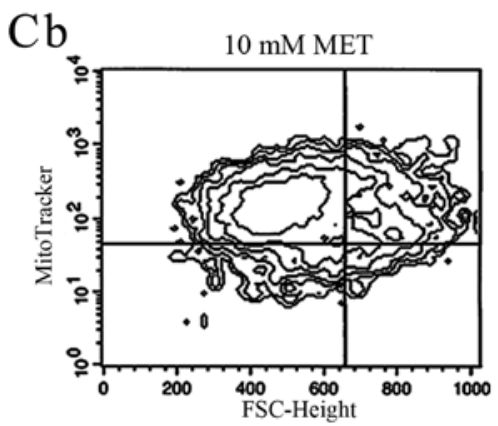

Figure 4. Effects of metformin (MET) treatment on mitochondrial structure and function. (A) Ishikawa cells treated with 10 mM MET for $48 \mathrm{~h}$ were stained with MitoTracker dye (red) and Hoechst 33342 (blue) to label mitochondria and nuclei, respectively (magnification, x180). MET treatment caused mitochondria to appear compact and disconnected compared to those in the control cells. (B) Flow cytometry analysis of MET-treated cells showed a dose-dependent decrease in MitoTracker fluorescence signal at 5 (blue) and 10 (green) mM MET compared to control cells (red). (C) Similar results were observed when the experiment was performed in cells treated with MET for $8 \mathrm{~h}$. (D) Lactate production increased with MET concentration, indicating increased glycolytic activity. Data are shown as mean \pm standard error of triplicate samples from three independent experiments. ${ }^{\ddagger} \mathrm{P}<0.01$.

treated with metformin for $48 \mathrm{~h}$ were stained with MitoTracker dye. Afterdrug treatment, the mitochondria were more compact, and connections between them were less apparent (Fig. 4A).
The intensity of staining decreased with higher concentrations of metformin (Fig. 4B). To exclude the effects of cell shrinkage that were observed after a 48-h exposure to metformin, the 
cells were stained and examined by flow cytometry after $8 \mathrm{~h}$ of drug treatment (Fig. 4C). Following metformin treatment, the fraction of cells with low levels of fluorescence was greater than that for the control cells, indicating that the decreased signal intensity in mitochondria induced by the drug was not due to reductions in cell size. Lactate concentrations in the culture medium were then measured, since glycolysis is stimulated by the impairment of mitochondrial function by metformin $(33,34)$. Lactate levels showed a dose-dependent increase following treatment with metformin (Fig. 4D). Taken together, these results indicate that cisplatin exerts anticancer effects in endometrial cancer cells that are potentiated by metformin under normoxic conditions, but during hypoxia, the additive effects of this drug combination are attenuated, which may be linked to the action of metformin on mitochondria.

\section{Discussion}

The results of the present study have demonstrated that metformin potentiates, without antagonizing, the anticancer effects of cisplatin in endometrial cancer cells under normoxic conditions. Cells treated with a combination of the two drugs had greater reductions in cell proliferation, as assessed by cell counts and thymidine incorporation, than cells treated with cisplatin alone (Fig. 2). Significantly, these additive effects were not observed at metformin concentrations of $0.1 \mathrm{mM}$. Thus, a combination treatment regimen of metformin and cisplatin may not be useful for endometrial cancer patients, since the lowest concentration of metformin tested in this study was several times higher than the clinically prescribed doses for the treatment of diabetes, which resulted in plasma metformin concentrations of $0.6 \pm 0.5 \mathrm{mg} / \mathrm{l}$ (22).

This discrepancy in dosing between in vitro studies and clinical observations is typically overlooked (5). Metformin uptake has been observed in many tissues (21), and this potential for accumulation in organs may necessitate concentrations that are higher than those indicated by plasma levels for effective cancer therapy (4). Other studies have shown that metformin does not accumulate in the plasma nor in any tissues other than the intestine, even with repeated administration (35). However, these results are from animal studies, and there are little data available on metformin levels in human organs (36).

Mitochondrial uncoupling proteins have been shown to prevent tumor growth in breast cancer cells (37). In Ishikawa cells, metformin treatment led to decreased staining with MitoTracker dye (Fig. 4), which is used as a measure of mitochondrial integrity (38). Thus, metformin likely inhibits cancer cell proliferation by inducing mitochondrial dysfunction. The present study also found that the additive effects of metformin in combination with cisplatin were attenuated under hypoxic conditions (Fig. 3). Metformin inhibits complex I of the respiratory chain in mitochondria $(33,34)$, which may not be relevant under low $\mathrm{O}_{2}$ conditions since this complex is involved in oxidative phosphorylation. Taken together, these results suggest that metformin has limited utility for endometrial cancer treatment, since tumor cells often exist in hypoxic microenvironments in which adaptive mechanisms enable them to thrive.

The first indications that metformin can be clinically beneficial for cancer patients were from epidemiological studies (1), in which cancer incidence and cancer-related mortality were found to be reduced in diabetic patients taking metformin $(2,3)$. Many patients with endometrial cancer have concurrent diabetes and insulin resistance (28-30), and obesity and insulin resistance are risk factors for endometrial cancer (39). Furthermore, in a retrospective analysis of neoadjuvant chemotherapy for breast cancer, metformin significantly increased the frequency of pathological complete response in diabetic compared to non-diabetic patients (40). Although in vitro studies have examined the direct effects of metformin on cancer cells, results of recent studies suggest that indirect effects may be important in tumor growth inhibition in vivo (5), for instance by lowering blood glucose and insulin levels (41). Thus, it is possible that metformin can be used effectively to treat endometrial cancer through combination treatments consisting of, for instance, the continuous administration of metformin and cyclic administration of cisplatin.

In conclusion, metformin potentiated the anticancer effects of cisplatin under normoxic conditions in vitro. Although these effects were attenuated under hypoxia, the reasons for which are to be the focus of future studies, there was no evidence of antagonism of cisplatin by metformin. Thus, the results offer the potential for a combination chemotherapeutic strategy that can be applied to endometrial cancer treatment.

\section{Acknowledgements}

This study was supported by the Japan Society for the Promotion of Science KAKENHI Grant-in-Aid for Young Scientists (B) (grant no. 24791686).

\section{References}

1. Evans JM, Donnelly LA, Emslie-Smith AM, et al: Metformin and reduced risk of cancer in diabetic patients. BMJ 330: 1304-1305, 2005.

2. Decensi A, Puntoni M, Goodwin P, et al: Metformin and cancer risk in diabetic patients: a systematic review and meta-analysis. Cancer Prev Res (Phila) 3: 1451-1461, 2010.

3. Noto $\mathrm{H}$, Goto A, Tsujimoto $\mathrm{T}$ and Noda M: Cancer risk in diabetic patients treated with metformin: a systematic review and meta-analysis. PLoS One 7: e33411, 2012.

4. Martin-Castillo B, Vazquez-Martin A, Oliveras-Ferraros C and Menendez JA: Metformin and cancer: doses, mechanisms and the dandelion and hormetic phenomena. Cell Cycle 9: 1057-1064, 2010.

5. Quinn BJ, Kitagawa H, Memmott RM, et al: Repositioning metformin for cancer prevention and treatment. Trends Endocrinol Metab 24: 469-480, 2013.

6. Hanna RK, Zhou C, Malloy KM, et al: Metformin potentiates the effects of paclitaxel in endometrial cancer cells through inhibition of cell proliferation and modulation of the mTOR pathway. Gynecol Oncol 125: 458-469, 2012.

7. Dong L, Zhou Q, Zhang Z, et al: Metformin sensitizes endometrial cancer cells to chemotherapy by repressing glyoxalase I expression. J Obstet Gynaecol Res 38: 1077-1085, 2012.

8. Shank JJ, Yang K, Ghannam J, et al: Metformin targets ovarian cancer stem cells in vitro and in vivo. Gynecol Oncol 127: 390-397, 2012.

9. Liu H, Scholz C, Zang C, et al: Metformin and the mTOR inhibitor everolimus (RAD001) sensitize breast cancer cells to the cytotoxic effect of chemotherapeutic drugs in vitro. Anticancer Res 32: 1627-1637, 2012.

10. Ashinuma H, Takiguchi Y, Kitazono S, et al: Antiproliferative action of metformin in human lung cancer cell lines. Oncol Rep 28: 8-14, 2012.

11. Rattan R, Graham RP, Maguire JL, et al: Metformin suppresses ovarian cancer growth and metastasis with enhancement of cisplatin cytotoxicity in vivo. Neoplasia 13: 483-491, 2011. 
12. Kim HG, Hien TT, Han EH, et al: Metformin inhibits P-glycoprotein expression via the NF- $\kappa B$ pathway and CRE transcriptional activity through AMPK activation. Br J Pharmacol 162: 1096-1108, 2011.

13. Rocha GZ, Dias MM, Ropelle ER, et al: Metformin amplifies chemotherapy-induced AMPK activation and antitumoral growth. Clin Cancer Res 17: 3993-4005, 2011.

14. Nilsson S, Huelsenbeck J and Fritz G: Mevalonate pathway inhibitors affect anticancer drug-induced cell death and DNA damage response of human sarcoma cells. Cancer Lett 304: 60-69, 2011

15. Iliopoulos D, Hirsch HA and Struhl K: Metformin decreases the dose of chemotherapy for prolonging tumor remission in mouse xenografts involving multiple cancer cell types. Cancer Res 71: 3196-3201, 2011.

16. Janjetovic K, Vucicevic L, Misirkic M, et al: Metformin reduces cisplatin-mediated apoptotic death of cancer cells through AMPK-independent activation of Akt. Eur J Pharmacol 651: $41-50,2011$

17. Yasmeen A, Beauchamp MC, Piura E, et al: Induction of apoptosis by metformin in epithelial ovarian cancer: involvement of the Bcl-2 family proteins. Gynecol Oncol 121: 492-498, 2011.

18. Harhaji-Trajkovic L, Vilimanovich U, Kravic-Stevovic T, et al: AMPK-mediated autophagy inhibits apoptosis in cisplatintreated tumour cells. J Cell Mol Med 13: 3644-3654, 2009.

19. Hirsch HA, Iliopoulos D, Tsichlis PN and Struhl K: Metformin selectively targets cancer stem cells, and acts together with chemotherapy to block tumor growth and prolong remission. Cancer Res 69: 7507-7511, 2009.

20. Gotlieb WH, Saumet J, Beauchamp MC, et al: In vitro metformin anti-neoplastic activity in epithelial ovarian cancer. Gynecol Oncol 110: 246-250, 2008.

21. Graham GG, Punt J, Arora M, et al: Clinical pharmacokinetics of metformin. Clin Pharmacokinet 50: 81-98, 2011.

22. Lalau JD, Lacroix C, Compagnon $\mathrm{P}$, et al: Role of metformin accumulation in metformin-associated lactic acidosis. Diabetes Care 18: 779-784, 1995

23. Martin MJ, Hayward R, Viros A and Marais R: Metformin accelerates the growth of BRAF V600E-driven melanoma by upregulating VEGF-A. Cancer Discov 2: 344-355, 2012.

24. Berridge MV, Herst PM and Tan AS: Tetrazolium dyes as tools in cell biology: new insights into their cellular reduction. Biotechnol Annu Rev 11: 127-152, 2005.

25. Ishiyama M, Miyazono $\mathrm{Y}$, Sasamoto $\mathrm{K}$, et al: A highly watersoluble disulfonated tetrazolium salt as a chromogenic indicator for NADH as well as cell viability. Talanta 44: 1299-1305, 1997.

26. Collier AC and Pritsos CA: The mitochondrial uncoupler dicumaro disrupts the MTT assay. Biochem Pharmacol 66: 281-287, 2003.
27. Pagliacci MC, Spinozzi F, Migliorati G, et al: Genistein inhibits tumour cell growth in vitro but enhances mitochondrial reduction of tetrazolium salts: a further pitfall in the use of the MTT assay for evaluating cell growth and survival. Eur J Cancer 29A: 1573-1577, 1993

28. Burzawa JK, Schmeler KM, Soliman PT, et al: Prospective evaluation of insulin resistance among endometrial cancer patients. Am J Obstet Gynecol 204: 355.e1-7, 2011.

29. Soliman PT, Wu D, Tortolero-Luna G, et al: Association between adiponectin, insulin resistance, and endometrial cancer. Cancer 106: 2376-2381, 2006.

30. Mu N, Zhu Y, Wang Y, et al: Insulin resistance: a significant risk factor of endometrial cancer. Gynecol Oncol 125: 751-757, 2012.

31. Johnson N, Bryant A, Miles T, et al: Adjuvant chemotherapy for endometrial cancer after hysterectomy. Cochrane Database Syst Rev 10: CD003175, 2011.

32. Vale CL, Tierney J, Bull SJ and Symonds PR: Chemotherapy for advanced, recurrent or metastatic endometrial carcinoma. Cochrane Database Syst Rev 8: CD003915, 2012.

33. El-Mir MY, Nogueira V, Fontaine E, et al: Dimethylbiguanide inhibits cell respiration via an indirect effect targeted on the respiratory chain complex I. J Biol Chem 275: 223-228, 2000

34. Owen MR, Doran E and Halestrap AP: Evidence that metformin exerts its anti-diabetic effects through inhibition of complex 1 of the mitochondrial respiratory chain. Biochem J 348: 607-614, 2000.

35. Wilcock $\mathrm{C}$ and Bailey CJ: Accumulation of metformin by tissues of the normal and diabetic mouse. Xenobiotica 24: 49-57, 1994.

36. Cantrell LF, Nelson CL, Gary RD and McIntyre IM: Fatal metformin intoxication with markedly elevated blood and liver concentrations. J Anal Toxicol 36: 657-659, 2012.

37. Sanchez-Alvarez R, Martinez-Outschoorn UE, Lamb R, et al: Mitochondrial dysfunction in breast cancer cells prevents tumor growth: understanding chemoprevention with metformin. Cell Cycle 12: 172-182, 2013

38. Poot M, Zhang YZ, Krämer JA, et al: Analysis of mitochondrial morphology and function with novel fixable fluorescent stains. J Histochem Cytochem 44: 1363-1372, 1996.

39. Renehan AG, Tyson M, Egger M, et al: Body-mass index and incidence of cancer: a systematic review and meta-analysis of prospective observational studies. Lancet 371: 569-578, 2008.

40. Jiralerspong S, Palla SL, Giordano SH, et al: Metformin and pathologic complete responses to neoadjuvant chemotherapy in diabetic patients with breast cancer. J Clin Oncol 27: 3297-3302, 2009.

41. Goodwin PJ, Pritchard KI, Ennis M, et al: Insulin-lowering effects of metformin in women with early breast cancer. Clin Breast Cancer 8: 501-505, 2008. 